\title{
A Clinical Study and Short Term Outcome of the Patients Presented with Thyroiditis
}

\author{
RAFIAAFROSE, ${ }_{1}^{1}$ HAM NAZMUL AHASAN,${ }^{2}$ APARNA DAS, ${ }^{3}$ GOBINDA BANIK,${ }^{4}$ ABED HUSSAIN KHAN, 5 MD. NAHIDUZZAMANE \\ SHAZZAD, ${ }^{6}$ ASHFAQUEAHMED SIDDIQUE, ${ }^{7}$ MOHAMMAD ASHIK IMRAN KHAN ${ }^{8}$, MOSTOFA KAMAL CHOWDHURY7 $^{7}$
}

\begin{abstract}
:
Thyroiditis-inflammation of thyroid gland includes a group of individual disorders having many different clinical presentations, aetiopathogenesis and histology. Sometimes they are overlapping on their presentations.

Objectives: To see the clinical biochemical profile and to observe a short term outcome of the patients presented with different types of thyroiditis.

Materials \& methods: 50 cases with clinical suspicion of thyroiditis were randomly selected. Clinical history, Physical examination and serum T3, T4, TSH was done in every patient and FNAC of thyroid gland \& TMab (Thyroid microsomal antibody) was estimated in some. They were followed up at three monthly intervals with the measurement of TSH.

Results: Cases were subdivided in to 3 groups. Among them subacute thyroiditis were 19 (38\%), 26 (52\%) were Hashimoto's thyroiditis and 5(10\%) were silent thyroiditis. The subacute group presented with features of hyperthyroidism, negligible RAIU (radioactive iodine uptake) and FNAC ( Fine Needle Aspiration Cytology) showed granulomatous thyroiditis. During follow up (57\%) became hypothyroid at 3 months, $(26 \%)$ euthyroid and (15\%) in thyrotoxic state. After 9 months (87\%) was hypothyroid and (5.26\%) thyrotoxic. At 12 months (94\%) was euthyroid and one thyrotoxic. Hashimoto's group presented in hypothyroid state, RAIU test were variable. FNAC showed lymphocytic infiltration in all patients. They were found $100 \%$ hypothyroid after I year. Silent Thyroiditis group were in hyperthyroid state with negligible RAIU. After 12 month (60\%) became euthyroid and (40\%) remain hypothyroid.

Conclusion: Thyroiditis has both thyrotoxic and hypothyroid phase but they are self limiting. So before giving specific therapy, thyroiditis must be excluded.
\end{abstract}

Keywords: Thyroiditis, Outcome, Hashimotos thyroiditis.

\section{Introduction}

Thyroiditis refers to inflammation of thyroid gland. This includes rare acute bacterial infection to rarest Riddles thyroiditis. The relatively common forms are sub acute or De Quervain's Hashimoto's, silent, postpartum and drug induced thyroiditis like amiodarone, interferon. ${ }^{1,2}$ All types of thyroiditis affect women more frequently than men and $3^{\text {rd }}$ to $5^{\text {th }}$ decades are the commonest age range..$^{3-8}$ There are some geographical and seasonal preponderance also. ${ }^{8,9}$ No symptoms unique to thyroiditis. The clinical course depends on their types. If the thyroiditis causes slow and chronic destruction, this would be a case of Hashimoto's thyroiditis ${ }^{2}$

1. Medical Officer, Dhaka Dental College Hospital

2. Professor \& Head, Dept. of Medicine, Dhaka Medical College Hospital

3. Asst. Prof. Dept. of Medicine, Dhaka Medical College Hospital

4. Lecturer. Deptt. of Pharmacology, Sir Salimullah Medical College.

5. Medical Officer, Dept. of Medicine, BSMMU

6. Medical Officer, Dept. of Medicine, BSMMU

7. Medical Officer, Dept. of Medicine, DMCH.

8. Medical Officer, 250 Beded Hospital Sadar, Gopalgonj

Correspondence: Dr. Rafia Afrose, Medical officer, Dhaka Dental College Hospital.
During the course of this disease, the cells of the thyroid become insufficient in converting iodine and "compensate" by enlarging. RAIU may be paradoxically high while the patient is hypothyroid because the gland retains the ability to "trap" iodine even after it has lost its ability to produce thyroid hormone. As the disease progresses the TSH increases and the patient becomes hypothyroid. This sequence of events can occur over a relatively short span of a few weeks or may take several years.

In subacute thyroiditis the thyroid gland generally swells rapidly and is very painful and tender. The gland discharges thyroid hormone into the blood and the patients become hyperthyroid; however, the gland quits taking up iodine. RAIU is very low, Patients frequently become ill with fever. Thyroid antibodies are not present in the blood, but the sedimentation rate is very high. Although this type of thyroiditis resembles an infection within the thyroid gland, no infectious agent has ever been identified, hyperthyroid phase lasts for 1-3 months as inflammation continues the gland often becomes depleted of thyroid hormone leading to hypothyroidism which lasts for 9-12 months. Total resolution occurs within 12-18 months. ${ }^{2,9}$ 
Silent thyroiditis is the third and least common type of thyroiditis. It was not recognized until the 1970 s, although it probably existed and was treated as Graves' disease before that. The blood thyroid test is high and the RAIU is low (like De Quervain's thyroiditis), but there is no pain and needle biopsy resembles Hashimoto's thyroiditis. The majority of patients have been young women following pregnancy which often considered as postpartum thyroiditis.

Antithyroid drugs have no role because thyroid hormone biosynthesis is already low. ${ }^{9}$ Levothyroxin is indicated during the hypothyroid phase in subacute \& silent thyroiditis when they are symptomatic and also in patients with Hashimoto's thyroiditis.

\section{Materials \& methods:}

This observational study was done on 50 cases with clinical suspicion of thyroiditis on the basis of painful thyroid gland, low RAIU test, patients with thyrotoxicosis or hypothyroidism and FNAC suggestive of thyroiditis. Pregnant and lactating mother and children below 15 years were excluded. Cases were selected from Thyroid clinic at nuclear medicine \& ultrasound centre in Khulna Medical College.

Comprehensive clinical history, physical examination and routine serum T3, T4, TSH and RAIU test were done in every patient and FNAC of thyroid gland \& TMab also was estimated in some. They were followed up at three monthly intervals with the measurement of TSH.

\section{Results:}

According to clinical presentation and investigation cases were subdivided in to 3 groups. Among them subacute thyroiditis were $19(38 \%), 26$ (52\%) were Hashimoto's thyroiditis and $5(10 \%)$ were silent thyroiditis. In sub acute group male $5 \&$ female 14 with a ratio of $F: M=2.8: 1$ mean age 32.11years . They presented with painful, tender thyromegaly, fever, palpitation, sweating, heat intolerance and tremor, raised T4 and reduced TSH in 17(89\%) and normal in 2(10\%). Negligible RAIU and FNAC showed granulomatous thyroiditis in $19(100 \%)$. During follow up 11(57\%) became hypothyroid at 3 months, $5(26 \%)$ became euthyroid and $3(15 \%)$ remains in thyrotoxic state. After 9 months 17 (87\%) was hypothyroid, 1 $(5.26 \%)$ thyrotoxic and one normal. At the end of 12 months 18 (94\%) was euthyroid and one remained thyrotoxic (Fig.-1).

Among Hashimoto's group male 2 (7.69\%) female 24 (92\%) $\mathrm{F}: \mathrm{M}=12: 1$ mean age 36.5 . They presented with generalized body ache, cold intolerance, constipation, weight gain, leg swelling of different percentages. Diffuse goiter found in 26 $(100 \%) \&$ delayed relaxation of ankle jerk in $18(69 \%)$. TableII $18(70 \%)$ had elevated TSH and reduced $\mathrm{T}_{4}$. RAIU test were variable. FNAC showed lymphocytic infiltration in all patients. They were followed up at 3 months interval and found 100\% hypothyroid after 1 year (Fig.-3).

Among silent thyroiditis group male 1 (20\%) female 4 (80\%) $\mathrm{F}: \mathrm{M}=4: 1$ mean age 27 . They were clinically and biochemically in hyperthyroid state with negligible RAIU $5(100 \%)$. At $1^{\text {st }}$ visit $3(60 \%)$ showed increased TSH, 1 (20\%) normal and 1 $(20 \%)$ had reduced TSH. At $2^{\text {nd }}$ and $3^{\text {rd }}$ visit $100 \%$ had increased TSH. After 12 month 3(60\%) became euthyroid and $2(40 \%)$ remain hypothyroid.

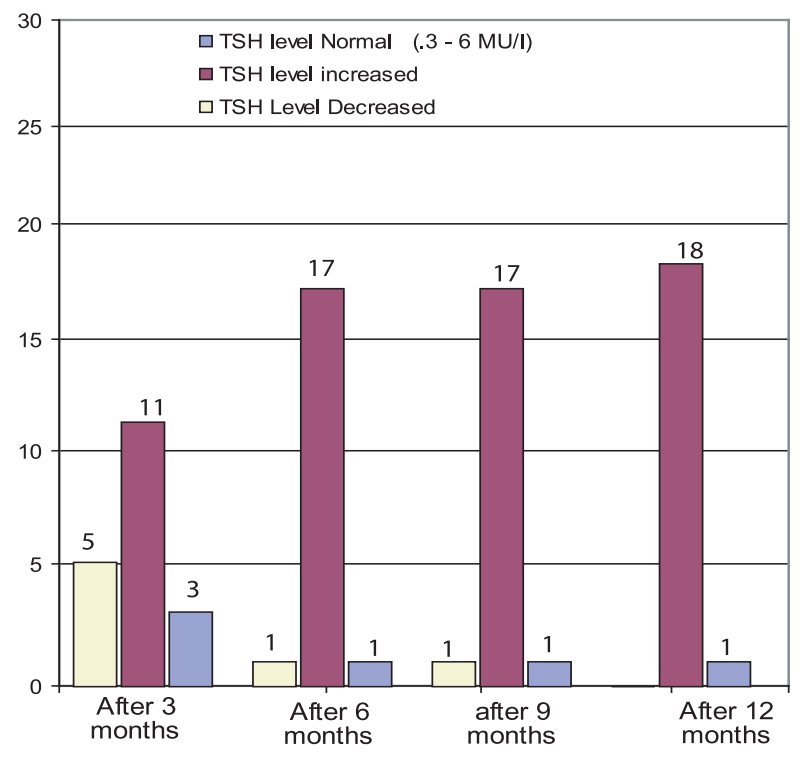

Fig. 1: One year follow up of patients with sub acute thyroiditis

Table-I

Symptoms \& signs of patients with subacute thyroiditis

\begin{tabular}{lcccccc}
\hline Symptoms \& signs & \multicolumn{2}{c}{ Total Number } & \multicolumn{2}{c}{ Male } & \multicolumn{2}{c}{ Female } \\
& No. & $\%$ & No. & $\%$ & No. & $\%$ \\
\hline Pain in the neck & 19 & 100 & 5 & 26.31 & 14 & 73.68 \\
Fever \& constitutional & 14 & 73.78 & 3 & 21.43 & 11 & 78.57 \\
Palpitation & 14 & 73.68 & 4 & 28.58 & 10 & 71.42 \\
Increased sweating and heat intolerance & 13 & 68.42 & 4 & 30.77 & 9 & 69.23 \\
Tremor & 12 & 63.15 & 3 & 25 & 9 & 75 \\
Dysphagia & 7 & 36 & 2 & 28.58 & 5 & 71.42 \\
Diarrhea & 6 & 32 & 2 & 33.34 & 4 & 66.66 \\
\hline
\end{tabular}


Table-II

Symtoms \& signs of patients with Hashimoto's thyroiditis

\begin{tabular}{|c|c|c|c|c|c|c|}
\hline \multirow[t]{2}{*}{ Symptoms \& signs } & \multicolumn{2}{|c|}{ Total Number } & \multicolumn{2}{|c|}{ Male } & \multicolumn{2}{|c|}{ Female } \\
\hline & No. & $\%$ & No. & $\overline{\%}$ & No. & $\%$ \\
\hline Cold intolerance & 14 & 53.84 & 0 & 0 & 14 & 100 \\
\hline Swelling of whole body & 3 & 11.38 & 0 & 0 & 3 & 100 \\
\hline Swelling of leg & 4 & 15.38 & 0 & 0 & 4 & 100 \\
\hline Weight gain & 12 & 46.15 & 1 & 8.33 & 11 & 91.66 \\
\hline Body ache & 11 & 42.30 & 0 & 0 & 11 & 100 \\
\hline Weakness & 12 & 46.15 & 0 & 0 & 12 & 100 \\
\hline Goitre & 26 & 100 & 2 & 7.69 & 24 & 92.30 \\
\hline Leg oedema & 17 & 65.38 & 1 & 5.88 & 16 & 94.11 \\
\hline Delayed relaxation of ankle jerk & 18 & 69.23 & 1 & 5.55 & 17 & 94.44 \\
\hline
\end{tabular}

Table-III

Symptoms \& signs of patients with silent thyroiditis

\begin{tabular}{lcccccc}
\hline Symptoms & \multicolumn{2}{c}{ Total Number } & \multicolumn{2}{c}{ Male } & \multicolumn{2}{c}{ Female } \\
& No. & $\%$ & No. & $\%$ & No. & $\%$ \\
\hline Palpitation & 3 & 60 & 1 & 33.33 & 2 & 66.66 \\
Heat intolerance & 3 & 60 & 1 & 33.33 & 2 & 66.66 \\
Weight loss & 2 & 40 & 1 & 50 & 1 & 50 \\
Goitre & 4 & 80 & 1 & 25 & 3 & 75 \\
Tachycardia & 3 & 60 & 1 & 33.33 & 2 & 66.66 \\
Tremor & 2 & 40 & 1 & 50 & 1 & 50 \\
\hline
\end{tabular}

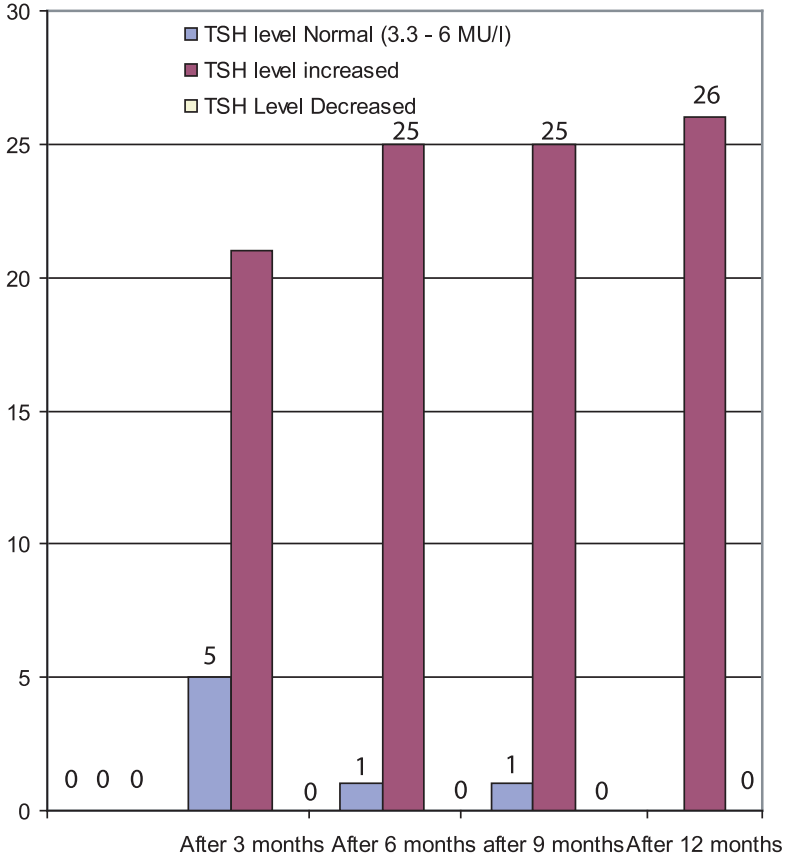

Fig.-2 : One year follow up of patients with Hashimoto's thyroiditis

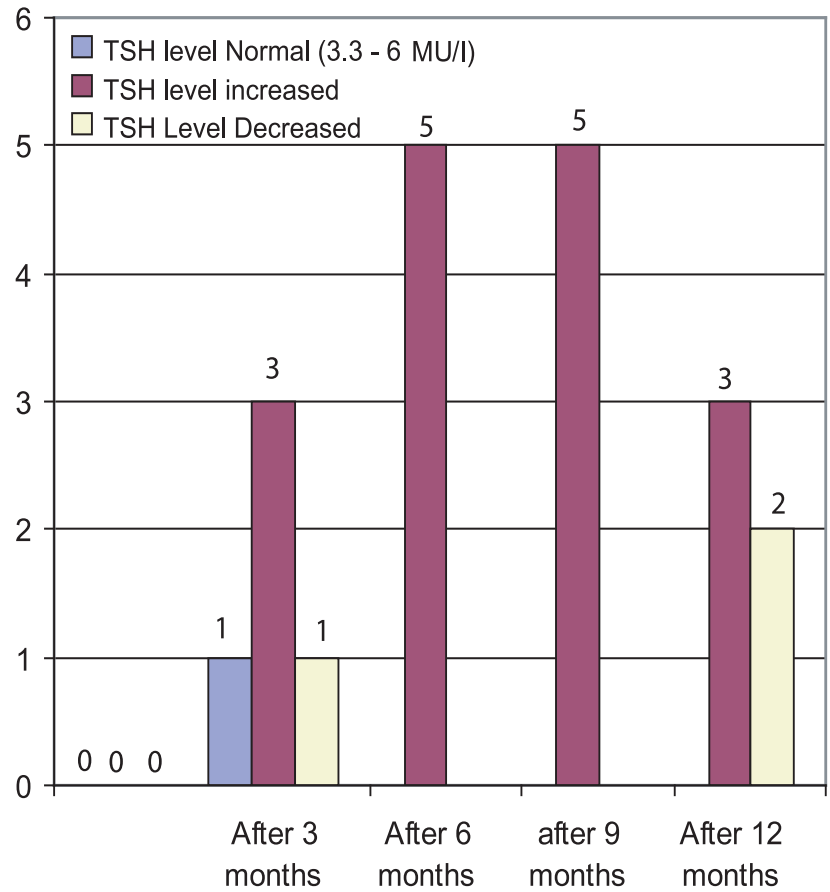

Fig.-3: One year follow up of patients with silent thyroiditis 


\section{Discussion}

Thyroiditis is a broad term, which include sub acute, Hashimoto's, silent, acute, fibrous and many other different types of thyroiditis. In this study the more common varieties are discussed. 50 patients of suspected thyroiditis were taken. They were again subdivided into subacute, Hashimoto's and silent thyroiditis group. Their clinical presentation, biochemical profile and 1 year follow up was observed.

Among 50 patients subacute thyroiditis were 19 (38\%), 26 $(52 \%)$ were Hashimoto's thyroiditis and 5(10\%) were silent thyroiditis. The ratio of Hashimoto's: sub acute: silent thyroiditis is 5.2: 3.8: 1 .

In subacute group male $5(26.32 \%)$ \& female $14(73.68 \%)$ with a ratio of $\mathrm{F}: \mathrm{M}=2.8: 1$ and mean age 32.11 years. The more common age groups were 15-40 years (Table-I). This incidence had similarity with previous study done by Badiuzzaman. ${ }^{10}$

Patients with subacute thyroiditis presented with painful, tender thyromegaly, fever, palpitation, sweating, heat intolerance and tremor of different percentages, raised $\mathrm{T} 4$ and reduced TSH in 17(89\%) and normal in 2(10\%). Negligible RAIU and FNAC showed granulomatous Thyroiditis in 19 (100\%). During follow up 11(57\%) became hypothyroid at 3 months, $5(26 \%)$ became euthyroid and $3(15 \%)$ remains in thyrotoxic state. After 9 months 17 (87\%) was hypothyroid, $1(5.26 \%)$ thyrotoxic and one normal. At the end of 12 months $18(94 \%)$ was euthyroid and $1(5.26 \%)$ remained thyrotoxic (Fig.-1). Ferdousi et al ${ }^{11}$ found the similar picture after one year follow up but the type of thyroiditis was not mentioned.

Therefore, the duration of thyrotoxic phase was between 13 months in most of the patients. Then the transient hypothyroid se of 9-12 months was observed. After 1 year $94.73 \%$ patients showed complete recovery \& $5.26 \%$ remain hyperthyroid.

Among 26 patients of Hashimoto's thyroiditis group male 2 (7.69\%) female 24 (92\%) F: $\mathrm{M}=12: 1$ mean age 36.5 years. Humbergor ${ }^{12}$ also described Hashimoto's thyroiditis as the commonest cause of goiter in USA. Our patients presented with generalized body ache, cold intolerance, constipation, weight gain, leg swelling of different percentages. Diffuse goiter found in $26(100 \%)$ \& delayed relaxation of ankle jerk in $18(69 \%)$ (Table-II). In case of $8(30 \%)$ the level of $\mathrm{T}_{3} \& \mathrm{~T}_{4}$ were in lower normal limit and TSH was in upper normal limit.18 (70\%) had elevated TSH with a reduction of $\mathrm{T}_{3} \& \mathrm{~T}_{4}$ value. RAIU test were variable. TMab was positive in $88.46 \%$ and FNAC showed lymphocytic infiltration in all patients. They were followed up at 3 months interval. $70 \%$ patients were hypothyroid at diagnosis and remain in the same status after 1 year. $30 \%$ patients were euthyroid at presentation but gradually turned into hypothyroid. So the ultimate outcome was hypothyroidism in all patients. Akira Sato ${ }^{13}$ et al showed in his ten year follow up study $66.2 \%$ euthyroid and $27 \%$ were hypothyroid among 74 patients. My study is not consistent with that study as the numbers of patients were small and the follow up time was only one year (Fig.-2).

5 patients out of 50 seemed to be the case of silent thyroiditis. Among them male 1 (20\%) female 4 (80\%) F: $\mathrm{M}=4: 1$ mean age 27. Similar incidence was found by Woolf ${ }^{14}$. They were clinically and biochemically in hyperthyroid state with no pain or tenderness, negligible RAIU $5(100 \%)$. At $1^{\text {st }}$ visit 3 $(60 \%)$ showed increased TSH, $1(20 \%)$ normal and $1(20 \%)$ had reduced TSH. AT $2^{\text {nd }}$ and $3^{\text {rd }}$ visit $100 \%$ had increased TSH. After 12 month 3(60\%) became euthyroid and $2(40 \%)$ remain hypothyroid. Amino ${ }^{15}$ et al showed the prevalence of thyrotoxic phase in silent thyroiditis among the patients with thyrotoxicosis was $4.9 \%$ (Fig.2).

Initially all the patients were hyperthyroid then $60 \%$ patients showed a period of transient hypothyroidism and became euthyroid within 9-12 months. $40 \%$ patients with silent thyroiditis had a tendency to remain hypothyroid. Similar results were found in western population ${ }^{16}$.

\section{Conclusion}

From the clinical stand point it is essential to differentiate different types of thyroiditis and other thyroidal illness. Subacute and silent thyroiditis have a transient (3-6 month) thyrotoxic phase similar to Grave's disease but has reduced RAIU. So before giving specific therapy to thyrotoxic patient, thyroiditis must be excluded. On the other hand Hashimoto's, subacute and silent variety, all passes through a phase of hypothyroidism. The former usually permanent and needs replacement therapy but the later two are self limiting so differentiation of these types of thyroiditis is also important.

\section{Conflict of Interest : None}

\section{References}

1. Schubert MF, Kountz DS. Thyroiditis; A disease with many faces. Postgraduate Med1995:98:101-112.

2. Yamamoto T, Sakamoto H, Spontaneous remission of hypothyroidism. Ann Intern Med 978; 88:808-9.

3. Alam MN. Haq SA. Ansari MAJ. Et al. Spectrum of thyroid disorders in (IPGM\&R) Dhaka, Bangladesh Med J 1995 ;6( $2): 53-58$.

4. Benbassat CA, Olchovsky D, Tsvetov G, Shimon I. Subacute thyroiditis: clinical characteristics and treatment outcome in fifty-six consecutive patients diagnosed between 1999 and 2005. J Endocrinol Invest 2007;30: 631-635. 
5. Volpe' R. Circulating viral and thyroid auto antibodies in sub acute thyroiditis J Clin Endocrinol Metab 1976;27:1275-84.

6. Erdem N, Erdogan M, Ozbek M, et al. Demographic and clinical features of patients with subacute thyroiditis: results of 169 patients from a single university center in Turkey. $\mathrm{J}$ Endocrinol Invest;2007; 30: 546-550

7. Nishimaki M, Isozaki O, Yoshihara A, Okubo Y, Takano K. Clinical characteristics of frequently recurring painless thyroiditis: contributions of higher thyroid hormone levels, younger onset, male gender, presence of thyroid autoantibody and absence of goiter to repeated recurrence. Endocr $\mathrm{J}$ 2009;56: 391-397.

8. Dayan CM, Daniels GH. Chronic autoimmune thyroiditis; N Engl J Med 1996; 335: 99-107.

9. Schubert MF, Kountz DS. Thyroiditis; A disease with many faces. Postgraduate Med1995;98:101-112.

10. Badiuzzaman M, Clinical and biochemical evaluation of sub acute thyroiditis, 2004;Dissertation 55-59.
11. Paul Ak. Ferdousi A. Alam MZ. Biochemical status of thyroid in pt. with thyroiditis. Bangladesh J. Nucl. Med 2004; 7 (2) :56-58.

12. Hamburger JI. The various presentation of thyroiditis. Diagnostic consideration. Ann Intrn Med 1986; 104(2): 219 224.

13. AkiraS., Toru A. Ten year follow up study of thyroid function in euthyroid patients with simple goiter or Hashimoto's disease, Inter Med 1995; 34(5):371-375.

14. Woolf Paul D. Painless thyroiditis as a cause of Hyperthyroidism: sub acute or chronic lymphocytic? Arc Intern Med vol. 138 Jan. 1978,p 26-27.

15. Amino N, Misato T. Autoimmune thyroid disease/thyroiditis. The "Thyroid gland". Endocrinology $3^{\text {rd }}$ End. Edited by Leslie De Groot pages: 720-741.

16. Nikolai TF, Brosseau J. Lymphocytic thyroiditis with spontaneously resolving hyperthyroidism (silent thyroiditis) Arch. Intern Med1980;140:478-82. 